\title{
Benefits and Challenges of Waste Recycling, a Field Study in Al- Diwaniyah Governorate
}

\author{
Ammar Subhy Shaker, Faez Saleh Mohammed ${ }^{\text {a) }}$ and Hawraa G.T.Al-Shebani \\ Faculty of Agriculture, University of Al-Qadisiah, Iraq. \\ a)Corresponding Author: faezsalih18@gmail.com
}

\section{Received : 24/5/2021 \\ Acceptance : 16/6/2021 \\ Available online: $31 / 12 / 2021$}

\begin{abstract}
Previous studies have resulted in many different countries and geographical regions in weather, terrain and activity The industrial sector to verify the extent to which the countries of the year benefit from recycling waste (1), The most important benefit is to reduce the volume and quantity The accumulated waste in the landfills that narrowed it down, which poses a threat to health and the environment, in addition to harming human senses and making use of basic materials suitable for industry, was doomed to be lost without benefit, with some remaining, such as glass and aluminum For long periods without decomposing or turning into part of the soil. And avoid the disposal of some of them, such as car oils And old tires in ways that lead to environmental pollution. What encourages countries to recycle some wastes such as glass, aluminum(2), wood and tires is that they are economically viable operations to the extent that many private companies compete in recycling them with the aim of profit due to the cost, energy and manufacturing requirements they provide without the need for huge capital or government support. By examining the possibility of applying waste recycling in the city of Diwaniyah to reduce the amount and volume of waste in it, it was not hidden from the economic feasibility of recycling wood waste, aluminum, glass, car oils and old tires even on a small scale, and that recycling operations will inevitably lead to a good economic recovery without the need for the state to bear a part of costs. As for household waste from aluminum cans and glass bottles(3), it needs recycling centers to collect, sort and prepare materials extracted from waste for recycling factories, and it also requires an expansion in the manufacturing process . This is also economically feasible, but it needs support from the state, local government, social institutions, and acceptance from the people. .In the case of matter, since it has a law that preserves it, it is transformed from materials that people benefit from and benefit from, even if he consumes them, they turn into waste or other chemical forms that are useless . However, if a person realizes the composition of waste, he will be able to recover the useful from it and use it again . Thus, this study provides results for the extent to which the city benefits from recycling industrial waste. The study focuses on recycled waste; Like:

-Wood : wood and sawdust waste from carpentry shops and furniture factories •

-Aluminum : aluminum waste from door and window workshops •

-Oils : used car oils •

-Tires : old tires $\bullet$

-Glass : leftover glass from glass shops, etc(4) •

The research answers some questions; Including : What are the quantities of this industrial waste in the city of Diwaniyah? What is the method that is currently being disposed of? Is there really a benefit from recycling waste? $\bullet$ Is the process of recycling economically viable(3); Or does the state bear part of its costs? Can the recycling process be applied in the city of Diwaniyah to reduce? the amount and volume of waste there, or not The research begins with a presentation of the problem of the accumulated waste from industrial activity and then turns to a presentation of ways to dispose of waste that accumulates very quickly in contemporary society. The research also presents details of a specific waste recycling process, namely wood, aluminum, and car waste from oils, tires, and glass . After that, the research deals with discussing the extent of benefiting from waste recycling at the present time, and the economic feasibility of recycling, including the entities funding the recycling process. The report concludes by addressing the issue of the possibility of applying the recycling process in the city of Diwaniyah to reduce the amount and volume of waste(5).
\end{abstract}

Keywords. Benefits, Al-Diwaniyah, Recycling.

\section{INTRODUCTION}

Waste is the materials that people dispose of daily as unwanted materials or useless objects or because they are holdings that are no longer usable and include surplus or spoiled food, damaged or dispensed equipment and household appliances, and empty containers from bottles And cans, boxes, plates, glass or smashed belongings, car tires, oils, and everything that 
ends up in a trash can or bin . Solid waste includes commercial waste and factory waste, which varies according to what they produce(6).

\section{RESULTS AND DISCUSSION}

\section{- $\quad$ Quantities of Solid Waste Quantities of Solid}

Waste are increasing rapidly in contemporary society in every part of the world as a result of the accumulation of industrial waste due to the steady increase in production and demand for products, and the increase in the volume of waste from developing commercial activities(7). The waste" solid " is growing with consumer societies in the world that exaggerates the canning consumption growth as well as the popularity of life based on the method of rapid change in products and short duration of its validity ; It has become one of the advantages that attract people to some products as it is valid for use only once, or it can be disposed of as waste after using it for a limited period. For this reason, it was not strange for modern societies to be called by a nickname ": The Throwing Society",in contrast to the previous societies, which kept everything and hardly got rid of any possessions ;And where the industry was proud of the production of long-lived. There is no doubt that the high level of solid waste generation from shops, factories and homes is due to the high standard of living in contemporary societies(5), obscenity in beautification and decorative packaging, exaggerated packaging, demand for singleuse items, cheap energy, production capacity, and population growth And the increase in the purchasing power of the general citizens

in many countries.

The accumulation of solid waste is a serious problem facing government interests at the local level because of the risks it poses to the environment and the health of the people, as well as distorting the aesthetic values of cities and nature.In addition to the hasty depletion of limited natural resources(1).

Through the field tours carried out by the problem research team, it was found that the waste specified in the research is disposed of through a sanitary landfill, where a hole is dug in the ground, the depth and capacity of which depends on the nature and quantity of the waste(1). With a drainage network for water resulting from rainwater and the processes of decomposition of organic materials found in some industrial waste. A solid layer of gravel and sand is placed over it to facilitate the entry of water into the drainage network. Waste is distributed at the base of the pit and stacked, so that the amount of compressed solid waste from $1-0.8$ ton per $\mathrm{m}$. 2And after the completion of the process of compacting the waste so that it reaches its height after the compression process $70-30 \mathrm{~cm}$ and a layer of construction waste ) ruble (is placed over it and it is tamped. On this layer of rubble, a second layer of waste is placed in the same way and so on until the site's height is reached50-30m and shrink the height of the site during20a year to about30\%from the original height. Where there is no isolation process for industrial waste such as tires, spent oils, glass, wood and aluminum from organic and household waste. And through the final data from the municipal sectors of the Diwaniyah Municipality Directorate, where all the waste for research is collected under the name of scrap, which is concentrated in the first municipal sector, which includes within its borders the industrial neighborhood of the city of Diwaniyah, in which most of the industrial waste covered in our research is concentrated, as well as the fifth municipal sector, which is from Within its borders are the Al-Jadida and Al-Fadiliya neighborhoods, which contain many shops for tires, oil changes, blacksmithing and carpentry shops(6).

Through joint cooperation with the Directorate of Environment of Qadisiyah, as well as with the Directorate of the Municipality of Al-Diwaniyah, and through experiencing the reality of industrial waste, collecting data related to it and comparing it with recognized international and local standards. Show the following

TABLE 1. The important problems associated with waste recycling (4).

Weak health awareness of shop owners as a result of the lack of awareness of the citizen, from any official or unofficial body, about waste, the method and its risks, how to benefit from it and employ it in

the absence of accumulation and the use of the correct scientific methods for collecting and recycling it

A deficit in the performance of the cadres for collecting and stacking waste, and this is due to the deficit in the old methods that are adopted in waste collection , as the worker is still using the shovels and the small cart compared to the large piles of industrial waste accumulated in the industrial and commercial areas

The city is heading towards sabotaging its environmental reality through the incorrect accumulation of waste piles in the so-called landfills
Raising the level of environmental awareness among citizens through the use of visual, audio and print media,

as well as places of worship to spread correct concepts about how to deal with waste and not to throw waste indiscriminately.

The use of specialized workers for the process of collecting waste and providing them with modern mechanisms, and not using workers of young ages, and this is what we found during coexistence .

Expedite the creation and encouragement of opportunities to attract investors to establish waste recycling plants for the purpose 
Sanitary landfills and the accompanying accumulation contrary to the scientific requirements of sanitary landfills

The lack of real information on the reality of waste in the governorate by the municipality ) it was found that they are only estimates ( and this leads to mishandling of waste in general and industrial waste in particular and a waste of public money
Re-manufacturing and converting them into useful raw materials, thus preserving natural resources and the environment and saving energy as manufacturing from raw materials

Doing a wide study of the current and future reality and providing modern technical methods to know what waste is generated and what raises it so that the accounts are accurate and dealt with accurately

\section{- $\quad$ Reducing The Production of Industrial Waste}

Of course, reducing the production of industrial waste at its source is a logical and noble goal, but it requires a change in the behavior of society on the one hand, and in the industrial and commercial system on the other. Reducing the volume of waste is achieved by making radical changes in the pattern of consumption and by adopting innovative methods in production and manufacturing;(1) For example : reduce consumption. Minimize the use of raw materials. The use of raw materials produce less waste and thus reducing waste is achieved. Follow green manufacturing approach (2).Use the waste as it is. Intended to suppress the rate of consumption or consumption rationalization in consumption it is difficult because the investigation requires : the introduction of amendments to modern living based on the method of obscenity in consumption. Changing trade - based methods call for more consumption of old and new to bring,(3) · pursuit of quick profit, and in order to avoid market stagnation. Development of the financial and economic system so as not intended to lead to a contraction in consumption - financial and economic relapse ; The contemporary economic system does not thrive except with an increase in consumption. The industrial orientation has shifted to inventing what benefits people instead of ensuring that products are designed so that the shelf life of the commodity does not exceed a limited short period, or work on the apparent change of the features of the products to replace the previous similar products that do not differ much from them in order to avoid market stagnation and in an effort to revive it. However, there are good efforts towards reducing the volume of waste in general and in some areas of consumption in particular. Stages of the recycling process The recycling process includes several basic stages ;she:

$\rightarrow$ Classification and sorting of waste and waste materials. .

$\rightarrow$ Waste and waste collection. •

$\rightarrow$ Preparing recyclable materials in waste and waste recycling centers. •

$\rightarrow$ Shipping the selected materials from waste and waste recycling centers to factories. .

$\rightarrow$ Recycling of materials recovered from waste and waste (5).

\section{- $\quad$ Classification and Sorting of Waste}

Since the technology of waste recycling requires handling a specific type of material to extract it, it is necessary to sort the waste(6) ; This requires the classification of solid waste in advance according to the manufactured materials, including those civil wastes, whether they are industrial or commercial waste, household waste, or waste that accumulates as a result of the 
activities of groups of people. There are wastes made of one substance and others that contain several substances . On the basis of classification, waste and waste are sorted. We limit ourselves to the important waste that is the subject of research,Usually, factories and large commercial establishments sort the waste before it is disposed of in huge garbage bins or prepared for transportation to centers directly by garbage trucks ; This is because factories usually work in one industry and control the collection of waste, which is huge in quantity and few in items . Large commercial establishments are also able to sort waste and transport it to landfills, incinerators, power stations or recycling centers(7).

\section{- Waste Collection}

Industrial companies and large commercial establishments usually transport the waste to its final settlement or to the recycling center with its own transport vehicles ; As for small establishments and commercial centers, the waste is collected in large bins collected by the authority supervising the collection of garbage. Recycling centers Recycling centers are the main downstream of recyclable materials from household, industrial and commercial waste ; Where waste and residues are sorted if necessary, and the sorted materials are packed in bales or tied in bundles and stored until they are sold to factories. Recycling plants There are factories that specialize in recycling one or more materials from waste and waste ;Also, some factories use limited percentages of these materials to manufacture their products(8).

\section{- Benefits of Waste Recycling}

There are many benefits that accrue to society from waste recycling ;the most important:

1. Reducing the demand for virgin raw resources.

2. Reduced energy consumption in preparation when recycling materials compared to preparing raw materials.

3. Control of local markets and sources of materials.

4. Reducing the costs of preparing land for landfill management, handling, transportation and burial of waste materials without a return on investment as a result.

5. Reducing or eliminating the risks surrounding the process of landfilling in the long term.

Reducing manufacturing costs and selling local products at competitive prices in the international market . And the energy savings used in preparing materials by recycling materials from waste may reach up to\% \%50of the energy consumed in the production of materials from their raw sources. There is no doubt that waste recycling is one of the successful investment projects that benefit the company and the country and get rid of the industrial effects of the factories. There is no doubt that such projects have very high and long-term financial returns as they contribute to preserving the environment significantly. But these projects require huge capital that these companies may not be able to carry out alone. However, the state's support for such projects gives it strength and allows the formation of major industrial companies specialized in this field, and the support of state ministries gives the subject a high industrial weight. There is no doubt that the countries of the industrialized world now benefit from the presence of these wastes and re-export them in a way that is used industrially and returns a financial return. In addition, it contributes to the process of preserving the environment (4). Recommendations and among the most important recommendations issued in the field of waste and waste recycling:

-The necessity of giving proper attention to waste recycling as an economic resource. • 
-Preparation of feasibility studies necessary to activate the benefit of tons per day of wasted · waste and waste.

-Conducting all feasibility studies of investment in the field of waste recycling and waste $\cdot$ call routing for those interested investors.

-Invite the state to provide various means of support and encouragement for all private sector companies $\cdot$ wishing to invest in the recycling of waste and waste.

-The State is also the task of public awareness of the people of the importance of cooperation from everyone in order to $\cdot$ activate the benefit of this resource important economic.

-Municipalities begin distributing bags and containers of waste on government industrial establishments private in the sector(9) especially in various colors once every week or every month so that allocates a certain color for all wood waste and other color for waste glass and other color for waste oil .. Thus, the municipalities develop a dedicated waste containers so that there is a waste of timber and container waste glass container .. Thus, .

-Holds the companies invested in the field of waste recycling and waste collecting containers $\cdot$ from similar waste so shall be recycled and invested in was in the interest of the national economy.

Among the positive results of this project are : protecting the environment from pollution resulting from industrial waste burials, preserving the lands used in the burial process, reducing the costs of organic fertilizer production, and saving the costs of its production from a sewage treatment plant(8).

\section{- Waste Wood}

Waste generally includes manufactured wood that is used in buildings, manufacturing, packaging, landscaping and demolition ;Examples of this type of waste are broken wood pieces, industrial wood such as plywood, particleboard( 10), wood scraps, and wood used in fences, roofs and sides of houses . As for industrial wood waste, it includes wood waste and sawdust from stores and furniture factories. The companies working in the timber industry are keen to reuse wood waste, recover its waste and recycle it in order to preserve the natural wealth of trees, as well as expand the provision of fiber products . However, producers of raw wood do not recycle wood or manufacture its waste resulting from other sources, and their use is limited to the waste of their factories, which they use to produce some of the energy they need.

Effects on the environment Wood recovery has many environmental benefits, including: Expanding the provision of fiber products, prolonging the life of their natural resources(11), contributing to carbon stocks, and reducing wood decomposition in landfills. This is in addition to contributing to the development of the technology of utilizing wood fibers recoveries . In fact, it is possible to recover more than\% \%80of wood scrap resulting from the manufacture of wood and raw wood in multiple uses(3).

\section{- Use of Waste}

Wood waste recovered from waste is used to fill many household needs and consumer products ; without the need to recycle. Covering rubbish dumps Sanitary dumps consist of cells for the disposal of solid waste(11). The cell is an area of the 
landfill where it is filled with garbage and then compressed and covered as a long-term means of waste disposal. The cover is necessary to reduce the leakage of water to the compressed waste under the backfill, to prevent waste from flying into the atmosphere, to reduce the spread of unpleasant odors, as well as to control the dump. Wood waste is probably the best material to cover the waste-filled cells . In this case, it is better to use relatively large pieces of waste, such as wood chips ; It is possible to use a mixture of various sized pieces for easy pressing of the mixture(5).

\section{- $\quad$ Agricultural Use}

Preventing weeds or controlling their growth on landscaped land requires the use of a light cover of wood residues because of the pores that allow the soil to breathe and facilitate the irrigation process while resisting the growth of unwanted weeds. The best types of wood waste that can be used in natural scenes are the waste resulting from wooden bases and wood that comes from doors, furniture, construction of mobile homes and sawdust shops. These ideal fibers do not give the lands of the natural scenes an elegant color, but it is possible to add colors to give the cover multiple colors of popular colors such as brown, black, red, as well as yellow and green. One of the advantages of the colored wood cover is that it does not decompose quickly and does not change the acidity of the soil, and it is also safe for the environment(12) .

\section{- $\quad$ Preparation and Maintenance of Home Gardens}

Use sticks, wood debris and slices to support small trees or climbing plants such as grapes . Wood powder cover follicular for the protection of trees and plants and basins cover uses $\cdot$ soil to strengthen its surface to prevent the growth of weeds to plant and to prevent erosion when irrigation and soil conservation and erosion of volatilization(1).

\section{- $\quad$ Strengthening the Sides of The Plant Pots}

By placing sawdust in heaps and moistening it, it decomposes and produces a fertilizer that nourishes the soil.

\section{- $\quad$ Filling Pits and Levelling The Ground.}

Mix mulch with soil to grow roses and potted plants. Use leftover wood debris as a cover for soft ground and pave a walkway over it and above .

\section{- $\quad$ Filling The Shortage of Fertilizer}

The process of natural fermentation of organic matter until it decomposes in order to add fertilizer requires adding a source of carbon and more porosity and increasing the solid contents of the compost mixture. Therefore, adding wood waste from sawdust dust that contains a small amount of moisture is a good way to fill the shortage of the mixture . where wood waste balances the mixture's carbon and nitrogen contents; Therefore, adding wood waste as a biological material to the vital solid materials from food waste ensures this balance and produces a mixture of materials that reform the soil as an excellent source of organic materials that nourish the agricultural land(4). 


\section{- $\quad$ Filling The Soil Deficiency}

In places rich in sand or silt. It is necessary to strengthen the soil by adding decomposed wood waste in a ratio of one part for every five parts of the original soil to increase the soil porosity to facilitate the growth of plant roots and their penetration into the soil and for the infiltration of surface water into it . In order to accelerate the decomposition of wood waste, add a nitrogen source from solid biomaterials or trim weed(5). Grass and alfalfa contain a high percentage of nitrogen.

\section{- $\quad$ Topsoil}

Topsoil is the upper part of the soil that is characterized by fertility because it contains a high level of plant food, organic matter and citrus fruits. Organic matter increases soil water absorption, cation exchange, tamping resistance, and soil microbial activity. This surface soil is what helps the growth of lawns, sports, vegetables, gardens, shrubs and the rest of the surface crops . For this, it is possible to use wood waste to provide the topsoil with organic matter to maintain its vitality . In this case, the wood waste is crushed and the flour plowed with the soil by one third. When wood flour decomposes, the nutrients are absorbed by the topsoil(12).

\section{- $\quad$ Potted}

Soil The soil of the plants is rich in nutrients that nourish the plants to ensure the growth of the plant roots and hold the irrigation water to saturate the roots while allowing the excess water to seep out. This soil often consists of $\% 60 \mathrm{wood}$ waste and the rest sand ; The wood provides the organic matter for soil moisture, while the sand helps the excess water infiltrate(5).

\section{- Animal}

Husbandry Various animals Wood waste is used in the construction of facilities for raising pets and domesticated animals, and food animals . It is best to use a mixture of dust, sawdust and small pieces of wood that have a moisture content of not more than \% 15 and should not contain non-woody materials or pollutants so as not to be a breeding ground for vermin and a cradle for bacteria. The wood must be moisture-absorbing in order to facilitate the removal of manure and the cleaning of urine places(12).

\section{- $\quad$ Energy Generation}

The wood that is extracted from waste for use in the co-generation of electricity is dried with hot air until its moisture decreases from $\%$ 15to \% 20Thus, its thermal energy contents range from 14 million joules per kilogram to 15 million joules per kilogram. Wood fuel is distinguished from fossil fuels by its low contents of sulfur and its compounds ;Therefore, the elevation of gaseous sulfur compounds and sulfuric acid are few, as well as the evolving carbon and nitrogen oxides that pollute the air are very low.

\section{- $\quad$ Paving Roads}

Addition of dense blocks of varying size of solid or similar wood to the muddy surface of motorways helps to stabilize the road ;Because it adds strength and cohesion to the road surface and facilitates the drainage of water away from the road ;This way, the road surface can better support the vehicle weights. These dense blocks of wood that are used in road consolidation 
can be from wood residues, provided that they are in the form of splinters of 8 millimeters or less in length . small wood chips are used for anchoring dirt roads, and parking spaces in factories ;Heavy equipment yards, maintenance corridors for municipal and railway departments, dumping entrances, and many unpaved car roads(3).

\section{- Wood Waste Recycling Products Industrial}

Is recycled to produce industrial wood and value-added wood compounds for the manufacture of furniture, etc.

\section{- $\quad$ Particleboard}

Wood is used in the manufacture of furniture cores and extracted from wood waste, where they are ground in a pulverized hammer into small particles, then covered with a cover of phenol resin adhesive, and the mixture is compressed under pressure and heat until it becomes coherent panels or to form it in different shapes. The particleboard is usually covered with a veneer or a glossy layer to improve its appearance. Since particle wood contains few fibers, its strength is all due to the glue used in its manufacture(13).

Wood chipboards and arranged wicking boards If the wood waste is large, it can be cleaned and then sliced into thin chips or fragments in the direction of the fibers with a length of about 30 millimeters and a thickness of one millimeter to manufacture wood boards of the type of packaging products that are used on surfaces and walls . There are two types of these boards, chip boards and arranged torsion boards. Foil boards are cast into a mat in the form of flat plates of randomly arranged wood chips collected by meat that is neither affected by water nor by boiling . As for the arranged wicking panels, they are made of wicking, on its front, chips are arranged lengthwise to give the panels strength in the longitudinal direction(12).

\section{- $\quad$ Wood Plastic One}

Of the methods used in recycling wood waste is mixing wood waste with plastic waste to produce a new type of manufactured wood, which is " plastic wood " composite. Wood is recycled for use as a filler for thermosetting plastics or thermoplastics. The characteristics of wood-plastic composite combine the strength of wood fibers and the ability of plastic to resist heat and moisture. There are many products using wood-plastic composites, wood-cement composites . And woodplastic panels made of plastic-mixtures are among the products that have been successfully promoted in the market . There is also a commercial product of wood plastic made from waste polymer recycling products and wood grain waste . The sources of polymer are waste bottles, containers, tubes, bags, tanks and tanks made of polyethylene . As for wood residues, they are all remnants of worn and broken wooden anchors. The product is characterized by the fact that it can be recycled to be recycled after use. In one of the manufacturing methods, plastic wood is manufactured by crushing scrap wood and plastic into fine particles that are mixed together and then using a magnet to remove any metallic materials from the mixture . The temperature of the mixture is raised until the polymer melts and covers the surface of the wood grains that are evenly distributed in the mixture. The liquid mixture is drawn and cast into the desired shapes and then cooled . There are many factories specialized in the manufacture of wood-plastic panels ; Some of them combine the recycling of plastic waste and the manufacture of plastic wood, and some of them depend on other facilities to prepare plastic material from scrap and waste.. The difference between them is in the quality of the plastic or the mixture of plastic used in manufacturing(11). 
- The Use of Plastic Wood

Wood is characterized by its durability and endurance to various weather changes and plastic wood panels are characterized by their resistance to corrosion, damage and rust, and suitability for any weather as it does not absorb moisture and does not interact with chemicals because it is chemically inert . Therefore, it is suitable in the manufacture of seats used in bus stops, decks, yachts, tables for public gardens, thresholds and wooden terraces for homes and public buildings, as well as wooden marine structures such as docks for boats, ships and ports. Wood-plastic panels are also used in complex alloys in the automobile industry(4). Although plastic wood is suitable for making furniture used outside buildings, it is not suitable for indoor furniture due to the inability to form it into precise or decorative combinations.. And the characteristics of wood plastic shock resistant, smashing and scratching qualifies for many other industrial uses such as Sirar automobile trailers industry, clashes trains and cars, and barriers to the side of the highway, blocks barriers dividing roads, cranes, bridges, thresholds, and barriers of anti-corrosion, etc. One of the plastic wood industries is the manufacture of hardware installation bases, where ordinary wood panels are used in addition to impact-resistant plastic wood panels. These bases are characterized by solidity, durability and slip resistance, in addition to the possibility of using low-priced and high-quality wood, as unbreakable plastic wood protects the base from damage or smashing if it falls from a height or crashes with a heavy object. Also, the base price is very low compared to the wooden base prices(13).

\section{- $\quad$ Reinforced Plastic Wood}

In some wood plastic products Reinforced plastic wood boards with steel tubes are also manufactured by recycling automobile scrap . Reinforced plastic wood is used in the manufacture of fence posts, whether square or round. These poles are easy to install in a reinforced concrete base and can be cut and punctured with the tools used in the case of wooden poles, except for the area of iron pipes that may need a metal saw. It is also used with nails and staples. (11) Reinforced plastic wood is also used for mailbox poles and gates and for carrying signs, signs and signals ; This is in addition to the retaining walls, anchorages for ships, boats, and stairs(1).

\section{- $\quad$ Generating Fuel Ethanol}

Is a liquid biofuel that is generated from biomass materials, which is extracted by converting starches and carbohydrates such as cellulose and compound cellulose into sugars and then fermenting the sugars. Wood waste suitable for ethanol production must be in the form of fine dust or ash so that the cellulose can be extracted and the ethanol concentrated(5)..

\section{- Industrial Gas Generation}

Gas is a fuel extracted from biomass materials and can be extracted from converting wood waste into gas for use as fuel for gas turbines. Industrial gas can also be used in the production of gas, diesel fuel and gas additives. The gasification process depends on the thermal decomposition of wood or its waste. (10) It is preferable to use wood waste that has a low moisture content in industrial gas generation to avoid the use of large energy in evaporating water before thermal decomposition(7). 


\section{- Methanol generation Methanol}

Is a liquid fuel extracted from industrial gas, where clean industrial gas is subjected to a transformational reaction to adjust the proportion of carbon and hydrogen in the process of artificial catalysis of methanol to produce raw methanol and then refine it before using it as fuel.

\section{- $\quad$ Cement Briquettes}

Adding wood residues or fly ash from coal as part of the solid materials to cement instead of sand and gravel, it produces a unique type of fossilized cement briquettes that can be used in construction or in reinforcement . It is characterized by mixing cement with a solid, low-strength material such as wood that the product is less dense and more efficient in thermal insulation and in absorbing noise. Also, the cement blocks manufactured by adding wood have a low compressive strength, which qualifies them for use in facilities that need light reinforced cement such as roadblocks, filling bumps, potholes and flattening. Wood scraps suitable for adding to cement include many sizes, from wood sharpeners ranging in size from crushed wood and wood dust to small, regular pieces ranging in length from 6, 19, 12 or even 20 millimeter(13).

\section{- $\quad$ Aluminum Waste Recycling of Aluminum Waste The Ability of Aluminum Waste and Scrap to Recycle}

Perhaps aluminum is one of the best recyclable metals in an economical and practical way to produce a good raw material for the manufacture of many metal products that have a large market around the world . One of the advantages of aluminum is that it can be recycled many times. That is, aluminum can withstand successive recycling processes without changing its quality level or decreasing its durability. (11) The manufacture of secondary aluminum ) waste (does not require more than $\%$ 5of the energy required to manufacture primary aluminum. Moreover, aluminum recycling is an independent, successful and profitable industry that does not require government support .

\section{- $\quad$ The Use of Recycled}

Aluminum Lightweight aluminum produced from recycling aluminum waste and scrap is used in the automobile, aircraft, and railroad cars industry, large and small household equipment, in construction and many other purposes.

\section{- $\quad$ The Use of Aluminum After Recycling in The Automotive}

Industry The transportation industry is one of the largest sectors that use aluminum as it is used in the manufacture of tires, structures, suspensions, and others. The use of aluminum in the automotive industry has increased steadily as a result of many of its advantages, which include the reduction of the weight of cars in order to fuel consumption, the possibility of recycling materials manufacturing, and homogeneity between the cutting car components, and the ability to withstand shocks, etc . One of the most important factors encouraging the automobile industry to use aluminum is its lightness, which leads to economic obstacles, including reducing oil consumption and environmental consequences, including reducing the emission of air pollutants. Also, the density of aluminum is one-third that of steel ;It is possible to manufacture a piece of aluminum car parts so that its thickness is one and a half times the thickness of a similar piece of steel while it is lighter than its counterpart.\% 50Just as an aluminum body can absorb twice the amount of energy that a steel body of the same weight absorbs . This is in addition to the aluminum's resistance to rust, in contrast to iron, which rusts under the same weather 
influences and requires coating it with a zinc cover to protect it.. The lightness of aluminum and its hardness improve the performance of the car, especially by reducing noise and vibration, ease of driving, speeding up and eliminating many undesirable characteristics. And in fact that $\%$ 85of spent car aluminum waste and all car industry waste is recycled and that the source $\% 60$ to $\% \% 70$ of the aluminum employed in the automobile industry is from the recycling of aluminum metal waste(13).

\section{- $\quad$ The Ease of Recycling Aluminum in Cars}

Is a witness to the ease of recycling aluminum. The large proportion of recycled aluminum used in cars today, which foretells of a long history of success and perseverance in the field of aluminum waste recovery and recycling . Among the known facts: About \% 60to \% About 70 percent of the aluminum used in modern cars comes from recycled metals. Although the aluminum contents of the car weight do not exceed $\% 5$ to $\% 10$ except that it represents $\% 35$ to $\% 50$ of the scrap value at the end of the vehicle's useful life. The amount of aluminum in the car structure that up to about $318 \mathrm{~kg}$ ranging value (14) in the scrap market between SR 938 and SR 1313 compared to the value of SAR 225 for the same weight of steel. As a result of supply and demand, manufactured aluminum scrap is recycled into ingots to increase the demand for it at present. The aluminum recycling industry is characterized by its ability to innovate and adapt to changes in the volume and mixture of waste. Although the development of technology such as automatic sorting of waste, the existing technology is still valid for aluminum recycling for decades to come. In fact, there is no need to design different cars or other sources of aluminum waste to facilitate its recycling; However, some foundations of appropriate design for recycling may increase the value of scrap recycling; Among those foundations:

$\rightarrow$ Clips, parts and accessories design for easy rolling. ·

$\rightarrow$ Work to increase the compatibility between related alloys by using one alloy or similar alloys whenever possible.

$\rightarrow$ Facilitating the removal of any part of the car or the like, especially large parts. .

$\rightarrow$ Careful to choose a certain quality of aluminum alloys that are easily recycled whenever $\cdot$ had the conditions and specifications(2).

\section{- Factories}

Recycling aluminum waste from door and window shops is a common practice in recycling non-ferrous metal scrap ;This is due to the ease of recycling it and the presence of many factories specialized in it, which treat it as any kind of scrap ;Recycling metal waste, such as aluminum; It is re-melted in aluminum foundries. Recycling Features The energy required to recycle aluminum cans is in some estimates approx\% 5 of the energy needed to manufacture these cans from raw materials, which means saving\% and reduce environmental pollution by $95 \% \% 95$ of bauxite obtained from mines . The majority of bauxite mines are in the rainforest region, which is rich in herbs important in the manufacture of drugs ;For this, drilling for bauxite extraction leads to dire consequences for the environment. And aluminum recycling costs are $20 \%$ Only 0 of its manufacturing $\operatorname{costs}(7)$.

\section{- Used Car}

Oils The content of used car oils on dioxin, which is found in petroleum products, poses a dilemma in its recycling. Valdioxin is a toxic substance that causes cancer. In fact, its danger results from the entry of any quantity, no matter how insignificant, into the respiratory or digestive system of humans or animals. Dioxin was used in the production of 
herbicides and agricultural pests . Despite the verification of the danger of dioxin on human health, France and Belgium added used car oils to animal feed to fatten animals, which led to the contamination of their European meat by discovering a case of dioxin contamination.. The main source is the use of dioxin-containing fats in the production of animal feed . The list of products likely to be contaminated with dioxin included fresh bird meat, beef and all meat preparations ) including gelatin that is extracted from animal legs or trotters, marshmallow sweets that contain gelatin and some frying fats, especially pork fat and meat products, milk and dairy products, eggs, and by-products). that contain more than \% 2eggs) a lot of cakes, pies and sweets (. There is a real danger to the environment when changing the car oil, whether in the repair shops or individually, because the spent oil contains dangerous substances that it picks up from the machine .Each liter of motor oil is enough to pollute 750 cubic meters of water, and the same fate is expected if it is disposed of in a landfill . And if it is spilled in a river, sea or lake, it will form a slippery layer that may reach 4000 square meters on the surface of the water(6).

\section{- Car Oil Recycling}

Numerous researches are conducted on how to recycle used car oils for reuse by adding chemicals to revive them after filtering and purification;These substances reduce the oxides formed in the oil ;Because the filter only gets rid of large particles , some kind of solids suspended in the oil, which accumulate in the oil as a result of erosion on metal surfaces(15).

\section{- $\quad$ Using Oil After Recycling It}

Is possible to recycle oils used in cars and use them as lubricating oil . As for recycling car oils to be used as another ball in cars, it requires filtering it from all impurities and then adding materials to reduce the oxide from it until it is revived again.

The benefits of working in this field amount to500In percent, and that there is no noticeable on the Aqaba entering that area, increased demand for oils after recycling after the expansion of the export operations. Recycling oils represents a profitable investment, and the owners of oil change centers are keen on used oils, after they used to dispose of them in a way that polluted the environment. He explained that the process of oil recycling goes through specialized equipment and machines, and the quality of the extracted oil depends on the quality and efficiency of the recycling machine, and physical compounds are added to it .90In percent of the original product quality . The machines manufactured in India are second in terms of quality to their German counterparts, and the quality of the extracted oil after recycling ranges between 75And 80 percent of the quality of the original product, and finally Chinese machines, which are usually of poor quality and do not exceed the quality of the oil extracted after recycling60In percent(3). The costs of setting up a factory to re -oil recycling vary depending on the production capacity of the plant to another, which starts from 10 thousand tons as the minimum limit, and increase according to the capacity of the factory, and the factory was established years ago in Saudi Arabia to recycle oil, production capacity100tons per day, at a cost of 16 million dollars . Factories bring used oils, through institutions specialized in assembling them, from maintenance centers and oil spare parts stores, and these institutions sell them to factories, as the price of used oils is approximately106dollars per ton, and is sold after recycling at about 613dollars per ton, with a profitability of more than fifty percent. The stage of oil recycling goes through several stages, including the process of cracking using heat, then comes the separation stage by adding some catalysts, followed by the stage of isolating impurities from the remaining oil, in addition to that the extracted oil decreases by a percentage 25In percent, representing impurities. Recycling oils produces more than one product, for example lubricating oils, and the type of sn500 From which hydraulic oil and other oils are produced, motor oil recycling is the method that can help protect the environment for future generations, while conserving energy resources. One meter of discarded oil is enough to pollute approximately 21 metres. The process of oil recycling lies in the removalof solid impuritiesand water, and through heating, easy to evaporate materials are removed.. He added that at the end of the rotation we get 80In percent of refined oil, this method does not require pressure or incentives, and are former recycling process through specialized machines in the recycling process(14).

\section{- $\quad$ Old Tires}

Include All kinds of tires such as buses, vans, cars, motorcycles, mechanics and some heavy equipment(11).

\section{- $\quad$ The Accumulation of Waste Tires}

Old worn out tires accumulate at a tremendous speed, especially in countries that depend on private cars for transportation. The amount of consumed tires per year may reach one tire per person ;In the year 2000, 300 million used tires were disposed of in the United States of America(8), and although more than half of this amount was recycled or used for other purposes, about 110 million tires legally ended up in landfills or were disposed of illegally to be added to the piles of abandoned tires that Over 800 million frames. In the industrial state of Pennsylvania in the United States of America, whose population does not exceed 12 million people, the tires that are disposed of annually as waste exceed 12million scrap tires, and while the state has cleaned and removed 20 million old tires during the past four years, the number of scrap tires accumulating in waste piles exceeds 16 million framework. 
The accumulation of old tires poses many risks to the environment and to the public health of citizens, especially those who live near dumpsites for the disposal of old tires ; This is in addition to eye damage, disturbance and distortion of nature from piles of worn tires. The rain water collects on the piles of tires in the dumps, and it generates an atmosphere that encourages the reproduction of mosquitoes that transmit infectious rain to people. In dry places and in dry seasons, it is easy for tires to catch fire. Experience has shown that large tire fires can continue to burn for weeks, if not months, despite every attempt to put them out; Which could lead to losses amounting to millions. The rubber of burning tires decomposes into oils and oil components that lead to the pollution of surface and ground water sources, along with harmful gases and carbon soot. In some areas, people get rid of old tires by throwing them into the river, which may threaten and destroy the natural coral reefs in the marine environment, and threaten seaweeds and the environments of marine creatures as a result of placing them on them .It also has an impact on marine cable lines and gas pipelines and endangering shipping lines(9).

\section{ALTERNATIVE WAYS TO DISPOSE OF WASTE TIRES}

\section{- Burning}

One of the methods used to get rid of tires is to burn them in special ovens ;However, this method has several drawbacks:

$\rightarrow$ The weight of the tires contains $\% 3$ of sulfur ; which leads to air pollution ;Also - There are difficult to dispose of ash and chaff.

$\rightarrow$ The steel in the tires remains unused.

$\rightarrow$ Burning generates zinc that rises into the atmosphere(7).

- Power Generation

Problem facing power generation from garbage containing old tires within the fuel is that it causes disruption in the fuel feeding line due to the viscosity of tires when they met before entering the combustion furnaces . However, tires can be shredded into small pieces or ground for use as fuel. However, the thermal energy that can be recovered from tires is considered to be inefficient if it is used to generate electric power(6).

\section{- Disadvantages of Recycling}

Perhaps the most complicated problem is the disposal or recycling of old tires ; The reason is due to the fact that it is no longer made of pure rubber, but many types of plastic and metal wire are mixed in it(15).

\section{- Advantages of Recycling}

Energy needed to produce a kilogram of rubber raw about 365 , mega Gul, while the energy required to rotate $\mathrm{kg}$ of rubber tires do not exceed 107 , megajoules a rate provision\% 71 of energy.

\section{- Uses of Recycled Tires}

The material resulting from recycling waste tires can be used in the manufacture of new tires . Ford Motor Company and Michelin Tire Company are also devising a way to manufacture tires containing\% 10of recycling spent tire materials 
without sacrificing durability or performance while driving. It is likely that this will reduce the rate of backfilling of tires in landfills by no less than 30 million tires, i.e. an average\% 12out of the number of tires that are discarded annually(15).

\section{- $\quad$ Manufacture of Rubber Products}

The material from waste tire recycling can be used to make hoses, insulating materials for electrical wires and tubes, adhesive tapes, car brake linings, carpet liners, and many other gym equipment and more(14).. Ford Motor Company recycles damaged tires and turns them into plastic struts for its cars. The Uniroyal Chemical Company is also working on manufacturing products from old tire alloys. The US Environmental Protection Agency has also drawn up a list of several old tire recycling products that the government must purchase to encourage recycling of tire materials ;Of which: Floor tiles, traffic barriers, cones to guide traffic, and road mats for runners(6).

\section{- Rubber Crumbs}

There is some shortcoming in the development of tire grinding technology, and the capital required to establish a tire grinding plant to extract its useful materials is very high, as it may reach between3the 4million dollars . However, there has been progress in the production and use of crumb rubber (8).

\section{- Uses Gestures Rubber}

Is worn tire manufactures crumbs rubber which is used in many purposes, the most important : control products in the traffic : obstacles speed, clashes cars, barriers - traffic, shock absorbers, rules Allaihat and guidelines, equipment sheds : reduce mud and dust, and ground Mtaod horse, and the land of the race $\cdot$ to mitigate the severity of the wound ;And mattresses for cows to increase milk production. Perforated and stamped products : seals, gaskets, pilings, nuts and insulators - Electric, etc . Rug products : floor tiles, mats and rugs ·. Roof products : roof tile and to repel rain - proof covers waterproof, material aspects of construction ', columns and walls. Lining for turf on golf courses . For Flatten products : sports and recreational equipment, Footnotes and inventory of ground play $\cdot$ and play tools ;And mats for comfort from stress, and rubber molded products for sports . Marine uses : anchorage bumpers and materials for anchorage and foundation .Scenes of natural engineering : additives for soil and water leakage, and materials to determine the edge $\cdot$,slabs twisted for decoration. Civil Engineering: Base Road, filler materials, and materials for flattening parking walkways . Railroad ferries and their links . Parts for cars and additional pieces ;Such as the lining of her bed, and Pushers mud, cover bottom, etc.

\section{- $\quad$ Asphalt Rubber}

Possible to grind waste tires and mix them with asphalt for paving roads, thus increasing the life of their surfaces by up to five times the life span of the surface when using asphalt alone; It also reduces the amount of raw materials used in paving. As one of the most important uses of rubber crumbs from recycling old tires is to add it to the asphalt employed in paving, paving and paving car roads, pedestrian sidewalks and airstrips . Asphalt rubber makes paved roads safer and more durable than ordinary asphalt due to its ability to bend in conditions of freezing and thawing under the influence of frost and to resist wear under the influence of wire-armored tires and in regular traffic situations . Asphalt rubber is also characterized 
as not eroding, cracking or splintering, and its validity lasts for long periods compared to any other paving materials . And many states in the United States of America, such as Texas, Florida, New Mexico, Arizona, and California, use asphalt rubber in paving roads as well as patching roads, especially wet roads.

\section{- $\quad$ Car}

Lifts Car lifts are made from rubber extracted from recycled used tires . Cranes are used to lift any type of car, regardless of its size, in repair shops to inspect it from below.

\section{- $\quad$ Oil Production}

Is possible to extract some oil by performing a pyrolysis process for tires or recover the basic components of tires by converting them to a liquid in a supercritical state ) supercritical liquid; ( The common factor in the two processes is the production of oil and gas and carbon blackening. The thermal decomposition process leads to : Pyrolysis oils are chemically unstable and contain a huge amount of sulfur. Thermal decomposition generates an amount of oils by $\% 24 l e s s$ than the extraction method - Basic tire components thermal decomposition generates the amount of gas by $\% 22 \mathrm{Below}$ is a method for extracting key tire components.

\section{- $\quad$ Tire Components Extraction}

A company extracts tire base components in a way that has several environmental benefits ;Including : getting rid of scrap tires, which are produced at a rate of one billion tires in the world annually. Separates sulfur as a byproduct of its use in other industries. The quality of oil produced in line with the requirements of the preservation of the environment ) less than 15 ppm of sulfur(10).

\section{- $\quad$ Benefits of Extracting Key Tire Components}

Eliminates the risks of fire associated with the accumulation of tires used in one place. Do not lead to the existence of a breeding ground for the breeding of insects and vermin. There is no lag behind waste from the process. The use of extracted soot in the production of activated carbon, which is used to filter and purify water and air. Energy Can 5 production 5 , million barrels of oil from 270 million pieces of waste $\cdot$ tires in the United States alone ; This is enough to produce 5 megawatts of electrical energy. The oil produced will be of crude oil grade No. 2Process plants can be satisfied with their energy needs by using their production of gas · thermal energy and part of the electricity that is generated from recovered oil. The process can be applied to derive renewable fuels from hydrocarbons through converted to gas or liquid. Soot recovery returning from soot constitutes $\% 45 \mathrm{of}$ the proceeds of the whole process. The purification of soot from the majority of the sulfur that contains it . Can remove zinc from soot, if necessary, can be used as active carbon soot in the industry or new tires and many other products(14).

\section{- $\quad$ Rotating Tire Wires}

When rotating tires, it is necessary to extract the wires made of steel, which are included in the installation of tires, to strengthen them. These wires can be recycled as scrap steel from cans, damaged household equipment, cars, 
and construction metals ; Iron scrap recycling in North America is considered one of the primary recycling processes for consumable materials, as more than 60 to 70 million tons of scrap are recycled annually . In fact, recycling a ton of scrap iron to make new iron saves $1135 \mathrm{~kg}$ of iron ores $636 \bullet \mathrm{kg}$ of coal 55 . kilograms of limestone . 11 mega joules of energy . This is in addition to the fact that all the iron produced contains $\% 25$ scrap iron recycling products(15).

\section{- Waste of Glass Properties of Glass Chemical Properties}

Glass is one of the inert chemical components that do not interact with the surrounding gases or liquids and therefore it retains its novelty and luster for a long term. Also, bottles and containers made of manufactured glass lack porosity, so they do not filter or leak out, or gas or liquid surrounding them 154 ;Therefore, the taste of what it contains does not change over time and its contents and flavor are preserved for a long time(16).

\section{- $\quad$ Natural Properties}

Glass is easy to shape at high temperatures. Glass melts at a temperature of 1500 degrees Celsius and becomes soft to be formed in various shapes, sizes and in the desired thickness, unlike plastic bottles and containers that sweat and pick up odors from the surrounding atmosphere and may interact with their contents . in it ;Therefore, it is used in the formation of test tubes and complex chemical laboratory devices. It was used in the manufacture of beads and jewelry for thousands of years ; It was also used from ancient historical eras in the formation of art holdings, windows, bottles and mirrors . By adding other materials to it, such as lead and copper, it is possible to manufacture colored glass for the decorations that are famous for the windows of Byzantine churches and temples. The glass is originally translucent, very transparent. However, it is possible to color glass to make statues, icons, and the like(11).

\section{- $\quad$ Glass Industry}

Virgin glass is made from a mixture of sand, soda ash and limestone ; Where the mixture is melted at a temperature of $1200^{\circ} \mathrm{C}$ until it is mixed. The manufacture of glass from sand is considered one of the most energy-consuming industries, as the process consumes about 18 megajoules of thermal energy to manufacture a kilogram of glass . Every ton of glass factory of raw materials produced $1261, \mathrm{~kg}$ of air pollutants and about $2268, \mathrm{~kg}$ of glass fragments as manure(16).

\section{- $\quad$ Classification of Glass Waste}

Attention here is limited to different sized leftover glass from glass shops. Flat glass may include : pieces and shards of flat glass sheets that may be clear or colored. An example of this type of glass is the glass of window openings, doors, tables, side windows of cars, and building and security glass ;But it does not include windshield glass in the front of cars, nor multilayered glass, nor curved glass . Composite glass : pieces and fragments of glass that contain composite materials. An example of this type of glass is car windshield windshield, crystal glass, mirrors, food dishes ) Chinese ,( pyrex and lighting lamps.

\section{- $\quad$ The Use of Glass Waste}

The crushed glass in the waste can be used as an alternative to sand in street paving operations. 
- Glass Recycling Re-Manufacturing

When glass is recycled or recycled, glass must be sorted according to its colors ) brown, green and clear ( to replace the raw materials.. The glass waste is crushed into small pieces ) glass scrap ( before being shipped to the factory to reduce the size . Scrap glass is passed through a magnetic device to remove the metal caps that may be mixed with it, and a vacuum device collects what may be mixed with scrap of paper, plastic or other impurities. After that, the scrap is melted to a high temperature for manufacturing, but the temperature is lower than the temperature needed to manufacture glass from the original raw materials. And crushed glass or glass residues are added to the raw glass. That is why the remnants of glass from glass shops, frames, etc., can be melted and shaped to produce small-sized products. Benefits of glass recycling Glass recycling consumes energy between $\%$ 68to \% 75less than that consumed glass processing of raw materials ; That is, making a glass bottle by recycling provides enough energy to operate a-100 watt electric light bulb for 4 hours.. Recycling glass leads to a reduction in air pollution by $\% 20$ And water pollution by $\% 50$ compared to manufacturing glass from raw materials(3).

\section{- Benefiting From Scrap Glass and Aluminium}

The major industrialized countries recycle some materials extracted from industrial waste for a purely economic motive ;Especially aluminum and glass waste whose recycling processes are characterized by advanced technology and economic feasibility. Among the factors that contribute to making the process of recycling these materials a profitable process are:

$\rightarrow$ Ease of possession of large quantities of industrial waste from limited and few places.

$\rightarrow$ There is no need for classification or sorting operations, or little effort and cost required in these operations.

$\rightarrow$ Industry sources need to be available and low price of raw materials , making it replace $\cdot$ it Albouksh scrap price.

$\rightarrow$ The need of the waste-producing industry to dispose of waste that does not benefit from it.

$\rightarrow$ The volume of industrial waste(17) .

- Utilizing Wood Waste

Industry waste does not constitute a tangible burden except on countries that have forests and natural wealth of trees that use them in the production of wood panels. However, factories that harvest wood and produce wood panels from trees consume waste to generate energy or sell large pieces of waste And inferior parts as fuel for heating or boiler furnaces . The wood factories themselves also recycle wood waste into other lower quality wood products to capture the market . Wood industry companies rarely accept wood waste from other sources because of the risk in quality and costs of purchasing, cleaning and preparing wood waste for recycling. Usually increasing wood residues in the rich wealth of national wood as a result of the spread based on the industries that use of wealth, such as the creation of houses, furniture and paper, either waste construction and demolition of the timber they are contaminated with paint and usually not suitable for reuse required to re Valmjhod use or to recycle such waste is not Equivalent to the abundance of new timber in the market at relatively low prices. (17) As for the remnants of the furniture industry, they do not exceed sawdust, plywood and scrap mixed with nails and other pollutants and may be tainted by some chemicals such as paint and solvents . This is why wood waste recycling plants are reluctant to use them;Very few furniture stores can benefit from cleaning it and selling it as scrap. Such waste 
usually ends up in incinerators, landfills, or power generation. Some of them may be used to provide agricultural requirements. In countries that lack wood wealth, their production of wood waste and sawdust is relatively small, but this does not prevent the establishment of special industries to recycle waste to manufacture types of lower quality wood boards(12).

\section{- Benefiting From Car Waste}

Despite the aggravation of the problem of waste generated by cars and their waste, the full use of such waste is still in the initial stages, although there is an urgent need to recycle such waste in some countries due to the aggravation of the problem of accumulation of such waste and the health risks to which societies are exposed And the environment from this accumulation. Benefiting from recycling used car oils. With regard to recycling used car oils, countries that do not produce those oils seek to recycle them, especially Japan and some European countries and poor countries . The obstacle to benefiting from the recycling of used car oils in some countries is : The produced oils are of lower quality than the original oils, especially in performance in severe weather - The coldness deteriorates the viscosity of the oils . Value of the car in many countries is very high, which makes consumer fear that $\cdot$ affect recycle used cars on the life of the car oils products . The low rate of car oil consumption as a result of the simple use of the car for transportation(6).

\section{- $\quad$ Benefiting From Recycling Old Tires}

United States, Japan and many European Union countries benefit from recycling old tires, whether in making new tires or in crushing rubber and using it to make other large products from household waste recycling. Benefiting from waste recycling

waste provides many benefits ;of which:

$\rightarrow$ Preserving the natural wealth of raw materials such as wood, aluminum and rubber.

$\rightarrow$ Limit space for dumps. .

$\rightarrow$ protect the environment from groundwater pollution and the spread of diseases from landfills ;Pollution · air from waste incineration;Soil pollution from toxic materials and non-chemically degradable materials.

$\rightarrow$ Obtaining materials that replace the need for raw materials in cases of necessity or scarcity(7). .

- Feasibility Study for The Establishment of a Recycling Plant for Industrial Waste in Al-Diwaniyah Governorate

Initial information : For the establishment of this project, the plot of land for the project must be located outside the basic design uses of the city, with an area of more than 1Approximately how many physical and chemical tests should be carried out for water and soil samples obtained from the area to show the quality of the soil and the properties of its groundwater. It should be close to landfill sites .Also, there should be no residential homes in the area, lack of commercial and industrial activities, far from highways and railways, and far from archaeological sites. And about the drinking water transmission lines, and that there are no mineral and oil resources in the area ,as well as the absence of agricultural and animal activities for that area. The objectives of the project The importance of the project lies in several aspects, including:

1. Reducing environmental pollution as a result of waste disposal through burial or incineration 
2. Preserving natural materials .

3. Reducing dependence on importing raw materials.

4. Providing new industrial opportunities.

5. Providing new employment opportunities and saving energy.

- $\quad$ Project Management and Operation

1. Continuously apply the guide to good environmental management.

2. Preserving the landscape and planting trees around the project .

3. Securing specialized and experienced manpower .

4. Adoption of the monitoring and monitoring program .

- Waste Recycling Costs

Whether the process of collecting and recycling waste is done by the private sector or the public sector, the capital needed to establish recycling centers and operating costs have increased rapidly during the previous decades . The costs of recycling per ton of recyclable materials in material recovery facilities in the United States of America, on average, amounted to about50dollar.; The total cost of collecting, sorting and recycling waste depends to a large extent on the quality or purity of the extracted materials and on whether the process of separating the waste contents is done manually or mechanically and on the process of purifying the desired materials. Also, many recycling cost estimates assume that the consumer will initially separate the waste and then deliver each type of waste to the recycling center. However, this is very costly for the consumer if we take into account the time, expense and energy required for the vehicle to transport small amounts of materials to recycling centers. The high costs of collecting and sorting recyclable materials, especially household waste, preparing them for marketing as secondary materials, and recycling them constitute an obstacle to achieving the economic feasibility of recycling materials from solid waste that accumulate after their consumption. The current custom is to sort the waste manually. The largest part of the costs of extracting useful materials from waste is the cost of labor, which amounts to \% 33 of the total costs. And the other costs from the installments of paying the costs of establishing the factory, transporting the wastes of the recycling process, disposal, maintenance and repair, amounting to 44 of the total costs . The annual costs of operating and maintaining a utility material separation facility are estimated at about \% 50 of the annual costs . And the cost of extracting materials from waste generally exceeds the cost of similar raw materials, especially high-value materials(9).

\section{- $\quad$ Quality and Costs}

Although campaigns advocating for waste recycling have an advertising, commercial and industrial base that they promote around the world and the presence of some companies constantly seeking to establish factories to recycle many of the municipal waste and industrial waste compilations, the technology is still behind . It seems that the industrial sector has found that if recycling programs are taken seriously, they can help reduce the cost of raw materials and operating costs, and improve their image as permanent accusers of environmental pollution. Despite the belief of some that waste recycling is the pinnacle of civility, after ten years of implementing the idea, many people in countries that widely implement recycling began to question the effectiveness of this process, and whether it is the best way to dispose of waste . They discovered with time that the cost of restarting is high compared to its advantages and return from it. The recycled product is usually lower in quality than the primary product used for the first time, and it is not used for the same purposes as the primary product. 
Despite this, the cost of manufacturing it is higher than the cost of manufacturing the basic product from its raw materials, which makes the recycling process economically illogical and even a waste of energy . If recycling is an ineffective way to get rid of waste, perhaps the best way to get rid of waste and at the same time not waste the non-renewable raw materials in it is to reduce its accumulation, and exploit it to generate clean energy or search for other uses for it to get rid of waste piles in a way Save the environment and don't waste energy.

\section{- $\quad$ Funding and Support Agencies}

Role of the government in recycling waste and waste is not a direct role, and there is no body that supervises the process of recycling industrial or commercial waste or household waste. However, there are government agencies that play an indirect moral role in encouraging waste and waste recycling.

- $\quad$ The Role of The Environment

Role of environmental protection includes:

$\rightarrow$ Age laws that include environmental protection and place restrictions on the pollution of the environment caused waste disposal and waste.

$\rightarrow$ Support projects that clean up landfills. .

$\rightarrow$ Supporting some research to create techniques that reduce the amount of waste and waste at its source.

$\rightarrow$ Supporting some research in extracting some valuable materials from waste and waste.

- $\quad$ Planning Requirements for The Waste Recycling Process

Most of the time, those in charge of waste management face severe problems in making appropriate decisions for their community regarding waste accumulation to choose an appropriate waste treatment system and reduce its volume in a manner consistent with the nature of waste generated within their jurisdiction. Indeed, modern technology has not drifted sometimes for several reasons, including: There are many different alternative ways and techniques ranging from reducing the volume - waste and reduce the accumulation to recycle to benefit from them. For each technical disadvantages and advantages of conflicting result contrast requirements of energy and natural sources · other, labor and skill level of workers, maintenance, management, safety, cleaning, and the amount of reliability on them, and the economies of scale, and the purity of backward material after processing. A particular area of waste are almost offense often waste in areas $\cdot$ other because the waste depend on the industry types in if there is the area of industry, commercial activity, tourist activity, consumer society and customs, there are a huge variation in the use of glass bottles, plastic and cans of aluminum from the community to another. Many waste treatment technologies have not been verified by the test of experience. Each class of waste may require special technical treads ·. Plurality of companies producing waste treatment systems between companies specializing in class - One of the waste and other offers multi - shelf systems . Therefore, the decision-maker must take some preparatory steps necessary to verify the technical feasibility of choosing the necessary techniques to reduce the volume of waste in his area and work to recycle the useful materials in it . Among those steps:

1. Taking note of the local peculiarities, statistics and data on the rate of waste generation.

2. Obtaining data on the types of waste and the possibilities of extracting useful materials from it. 
3. Knowing the methods of available technologies, their cost, performance efficiency, and requirements.

4. Nomination of the appropriate technology for the type and quantity of waste, taking into account the compatibility between it and local peculiarities and the people's acceptance of it. This may necessitate the use of international institutions and companies that provide assistance to the municipal administration in setting up an integrated system for continuous supervision and control of the amount of waste under local restrictions and data.

5. Ensuring the market needs the materials to be recycled to be used as raw materials for industry ; That is, the willingness of manufacturers to purchase raw materials produced by the recycling process.

6. Ensure that there are markets for the materials produced from the recycling process.

7. Verify the positive impact on the quantities of waste that are disposed of in landfills after extracting useful materials from them.

8. Create a bank or database to connect the vendor ) who collects waste or who sorts waste( .Finding effective means of transportation and recycling and an efficient system for collecting and preparing ) cleaning, sorting, packing, shredding, washing, etc, and shipping recycled materials to manufacturers.

9. Verify the ability to control quality 192 and maintain a level of quality for recycled materials so that they can compete with virgin raw materials.

10. Carry out an extensive market study for products that use recycled materials ;Including sensitivity to the consumer's position and preference among goods, and choosing the appropriate selling price for the consumer,

11. The successful application of the foundations and arts of industrial systems and quality engineering on recycling methods.

12. The absolute acceptance of the consumer for the goods produced from the returned materials is a key factor in the success of the recycling process ; It is not enough to use the slogans of protecting the environment, or beautifying the country, or counting the merits of the good things that may befall the country, or preserving the natural resources for future generations. These slogans may be feasible in a short period, but they do not establish a market that has solid foundations that can be relied upon. And to identify the need for advertising, and examine other factors that affect marketing to consumers(18).

\section{- $\quad$ The Possibility of Applying Waste Recycling in The Project}

No doubt that the recycling of wood waste and sawdust from Almnajer and furniture factories in the city, which accumulate with the expansion of wood industries and increase production will have several benefits, the most important : the exploitation of available materials to be virtually utility useless in the quality of the industry of wood have $\cdot$ large market in the region. Providing employment for technicians and chemists .Open the door for private investment in the industry is inexpensive and does not require much capital $\cdot$. Reduce the total volume of waste final disposal of wood waste and lack of waste $\cdot$ recycling . Perhaps the best product for recycling this type of wood waste is the particleboard industry, which does not require much equipment, does not take up much space and does not require unavailable skills . Particleboard is one of the best types of wood in the manufacture of cupboards, simple tables, shelves for bookcases and children's furniture . To achieve this, the recycling factory must collect wood waste from furniture-making workshops and carpentry shops or buy it from them in size so that the owners of those shops are keen on the cleanliness of the waste and not pollute it with paints and 
purify it from nails. It is expected that the wood waste will be easily transferred from the quarries to the recycling plant due to the relative proximity between the quarries sites. It is necessary to know the amount of waste and the rate of its production. However, it is possible for the factory to operate seasonally if it is attached to some existing stores(19).

\section{- $\quad$ Aluminium Waste}

Recycling aluminum waste from door and window workplaces in the city of Al-Diwaniyah may encounter some difficulties, the most important of which are: The size of waste aluminum shops work doors and windows in the city may not be enough to finance raw materials for the factory re - manufacturing of aluminum throughout the year . High cost of aluminum recycling plant in case of modest production;Vaguetsadiat size are important in this case. Reduction in production costs by increasing its volume. However, it is possible to recycle aluminum waste by an existing factory for the manufacture of aluminum ;By adding the waste to the raw materials used in production. Alternatively, the waste can be shipped to an aluminum factory elsewhere(20) .

\section{- Used Car Oils}

Possible to recycle used car oils in the city in some car maintenance workshops by filtering and reusing it ;It is possible to extend its life by adding chemical additives to reduce the small oxide atoms that may remain in it. It is possible for the recycling process to be carried out by one of the major maintenance workshops, provided that it undertakes to collect the used oils from other workshops for a small sum of money, or it should carry out the recycling process for a fee and then return it to the workshops. This practice requires selling oils to those who wish to buy them at a price that is competitive with the price of unused oils. The used oils can also be collected and shipped to recycling plants to be established in the Kingdom.

\section{- $\quad$ Old Tires}

There is no doubt that the quantities of old tires are accumulating very quickly in the city of Al-Diwaniyah and its surroundings. Perhaps the simplest, least expensive and fastest way to rotate these tires is to build a workshop that does the following:

$\rightarrow$ Tire cleaning. •

$\rightarrow$ Separate worn out tires from worn-out tires. •

$\rightarrow$ Restore what works from tires and sell them as used tires with a short life.

$\rightarrow$ Shredding with a mechanical chopper · ;Selling rubber crumbs. The market for crumb rubber is a large open market ;And if the area does not know it, it can be sold for the interest of paving roads to add it to the asphalt and use it as a ground mat in some places such as children's playgrounds, camps and others . Of course, it can be used in the manufacture of traffic barriers.

\section{- Glass Waste The Glass Waste}

Recycling industry is easy and inexpensive and can be implemented on a small scale without a large capital . In fact, there are many people who engage in glass recycling as an entertaining hobby ; They use it in the formation of many artefacts and decorative windows . It is enough to start with one factory that collects glass waste from the shops and recycles it (7). 
Some house waste, such as aluminium cans and glass bottles, in the city of Al-Diwaniyah is characterized by a huge size and huge quantity;For this, it is possible to recycle it to take advantage of the materials it contains and reduce the amount and volume of waste. Recycling aluminium and glass bottles is technically feasible and economically feasible . Aluminium cans In the case of aluminium, a factory can be set up to recycle aluminium waste from homes after adding aluminium waste from door and window workplaces. What is required in this case is to develop an economic plan to collect aluminium cans from homes and shops in a manner that matches the nature of society and is acceptable to the people . The idea of encouraging people to separate and collect cans and sell them to the factory by weight or by number may be one of the preferred ways. The huge quantities of aluminium cans that end up in bins and garbage cans during the Hajj seasons are rich in operating the factory throughout the year. This solves the problem of the small size due to the small amount of store waste(4).

\section{- $\quad$ Glass Bottles}

Is better to collect household waste from glass bottles in isolation from glass residues from glass shops because of their different types ; However, it is possible to recycle both types of glass in the same factory by single operations.

\section{- $\quad$ Reducing The Amount and Volume of Waste}

There is no doubt that the amount and volume of waste in the city of Diwaniyah is steadily increasing as a result of the urban movement that it is witnessing at the present time, as well as industries related to construction such as carpentry factories, furniture factories, door and window shops, glass shops and frames . Perhaps one of the useful results of identifying the problem of waste accumulation and methods of disposal and investigating the economic feasibility of waste and waste recycling is to find optimal ways to reduce the amount and volume of waste in the city of Diwaniyah . The following are some possible ways that are consistent with the nature and characteristics of the city and that can be implemented in a short period of time : Establishing a major center for waste recycling Due to the variation in the quantity and volume of waste and waste production throughout the year, it is preferable to establish a waste recycling center in an accessible place ;The Center 's mission include : waste collection containing easy recycling of materials characterized by that recycling · economically inefficient and market products manufactured active ;Such as wood, sawdust and furniture factory waste ;aluminum waste from door and window workplaces ;remnants of glass from glass shops, frames, etc ;.And old tires, and leftovers from homes and human gatherings of aluminum cans and glass bottles. Waste sorting and cleaning $\cdot$. Pressure waste size mechanically and prepare them for manufacturing $\cdot$. Do and sell them shipped to factories $\cdot$. Material storage until it is sold $\cdot$. It is better that the center creates a private company receives blessing from the municipal administration and moral support from the local government. The center begins its activity by encouraging people and commercial and industrial establishments to provide it with the specified waste and sell it to the center, and it is possible to cooperate with the municipality on a plan to collect the specified materials from homes and garbage bins.. A program to encourage waste recycling Although projects for recycling industrial and commercial waste from wood, aluminum ,glass, oil and rubber are economically feasible, to start it requires an awareness campaign through seminars and meetings with individuals or institutions that can implement these projects(18) . It may be necessary to provide some material incentives from the state or local government(6). 


\section{REFERENCES}

[1] Cobo, M.J.; López-Herrera, A.G.; Herrera-Viedma, E.; Herrera, F. SciMAT: A new science mapping analysis software tool. J. Am. Soc. Inf. Sci. Technol. 2012, 63, 1609-1630.

[2] Wang, Y.; Long, X.; Li, L.; Wang, Q.; Ding, X.; Cai, S. Extending theory of planned behavior in household waste sorting in China: The moderating effect of knowledge, personal involvement, and moral responsibility. Environ. Dev. Sustain. 2020.

[3] Fawzi, M.N., \& Mahdi, A.B. (2014). Iraq's inland water quality and their impact on the NorthWestern Arabian Gulf. Marsh Bulletin, 9 (1), 1-22.

[4] Tonglet, M.; Phillips, P.S.; Bates, M.P. Determining the drivers for householder pro-environmental behaviour: Waste minimization compared to recycling. Resour. Conserv. Recycl. 2004, 42, $27-48$.

[5] Carrus, G.; Passafaro, P.; Bonnes, M. Emotions, habits and rational choices in ecological behaviours: The case of recycling and use of public transportation. J. Environ. Psychol. 2008, 28, 51-62.

[6] Berglund, C. The assessment of households' recycling costs: The role of personal motives. Ecol. Econ. 2006, 56, 560-569.

[7] Vining, J.; Ebreo, A. What makes a recycler? Environ. Behav. 2016, 22, 55-73.

[8] Garfield, E. Historiographic mapping of knowledge domains literature. J. Inf. Sci. 2016, 30, 119-145.

[9] Rajendran, S.; Hodzic, A.; Scelsi, L.; Hayes, S.; Soutis, C.; AlMa'adeed, M.; Kahraman, R. Plastics recycling: Insights into life cycle impact assessment methods. Plast. Rubber Compos. 2013, 42, 1-10.

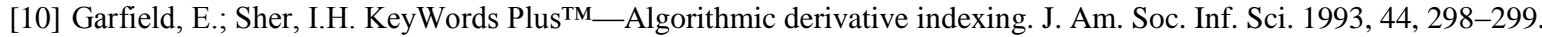

[11] Fernández-González, J.M.; Díaz-López, C.; Martín-Pascual, J.; Zamorano, M. Recycling organic fraction of municipal solid waste: Systematic literature review and bibliometric analysis of research trends. Sustainability 2020, 12, 4798.

[12] Cahlik, T. Comparison of the maps of science. Scientometrics 2000, 49, 373-387.

[13] Ma, J.; Hipel, K.W. Exploring social dimensions of municipal solid waste management around the globe-A systematic literature review. Waste Manag. 2016, 56, 3-12.

[14] Saphores, J.-D.M.; Nixon, H. How effective are current household recycling policies? Results from a national survey of U.S. households. Resour. Conserv. Recycl. 2014, 92, 1-10.

[15] Lizin, S.; Van Dael, M.; Van Passel, S. Battery pack recycling: Behaviour change interventions derived from an integrative theory of planned behaviour study. Resour. Conserv. Recycl. 2017, 122, 66-82.

[16] Hameed, M., Ahmadalipour, A., \& Moradkhani, H. (2018). Apprehensive drought characteristics over Iraq: results of a multidecadal spatiotemporal assessment. Geosciences, 8(2), 58.

[17] White, K.M.; Hyde, M.K. The role of self-perceptions in the prediction of household recycling behavior in Australia. Environ. Behav. 2011, 44, 785-799.

[18] Tsai, F.M.; Bui, T.-D.; Tseng, M.-L.; Lim, M.K.; Hu, J. Municipal solid waste management in a circular economy: A data-driven bibliometric analysis. J. Clean. Prod. 2020, 275, 124132.

[19] Cobo, M.J.; López-Herrera, A.G.; Herrera-Viedma, E.; Herrera, F. SciMAT: A new science mapping analysis software tool. J. Am. Soc. Inf. Sci. Technol. 2012, 63, 1609-1630.

[20] Bamberg, S.; Möser, G. Twenty years after Hines, Hungerford, and Tomera: A new meta-analysis of psycho-social determinants of pro-environmental behaviour. J. Environ. Psychol. 2007, 27, 14-25. 